\title{
DESAIN PAPAN INFOGRAFIK UNTUK POLITEKNIK NEGERI SAMARINDA
}

\author{
Dwi Cahyadi \\ Staf Pengajar Program Studi Desain Produk, Jurusan Desain \\ Politeknik Negeri Samarinda \\ e-mail: dwi_polnes@yahoo.co.id \\ Apri Yani Nur Adilla \\ Mahasiswa Program Studi Desain Produk, Jurusan Desain \\ Politeknik Negeri Samarinda
}

\begin{abstract}
ABSTRAK
Sebagai salah satu lembaga pendidikan yang diberikan tugas untuk mewujudkan tujuan pendidikan nasional, suatu pendidikan tinggi harus menjalankan perannya dengan baik. Komponen dalam perencanaan yang strategis paling tidak terdiri dari informasi tata letak bangunan. Pada institusi pendidikan sering kita dapati media informasi tata letak bangunan dengan bentuk standar persegi sehingga hal ini kurang mengundang perhatian orang untuk melihat media tersebut pada suatu intitusi pendidikan tersebut. Politeknik Negeri Samarinda sebagai institusi pendidikan mempunyai gedung Direktorat sebagai tempat untuk melakukan berbagai aktivitas yang berkaitan dengan kegiatan yang memiliki maket Politeknik Negeri Samarinda sebagai media informasi mengenai tata letak bangunan dari Politeknik Negeri Samarinda yang dapat dibaca oleh civitas akademika Politeknik Negeri Samarinda. Maket yang ada di Direktorat masih terdapat kekurangan. Hal itu dapat terlihat dari bentuk desain yang standar persegi. Bentuknya yang tidak estetis memiliki kekurangan yaitu terdapat sudut tajam pada bagian maket seringkali tak sengaja melukai para pengguna. Selain itu, selama ini maket yang ada di Direktorat Politeknik Negeri Samarinda tidak memiliki fungsi lain. Papan infografik yang didesain sesuai kebutuhan dan mempunyai fungsi tambahan sebagai tempat brosur sehingga lebih efektif digunakan karena lebih fungsional, lebih tahan lama dan dapat menarik minat pembaca.
\end{abstract}

Kata kunci: Papan Infografik, Tampilan, Berdiri 


\begin{abstract}
As one of the educational institutions given the task to realize the goals of national education, a higher education must perform its role well. Components in strategic planning at least consist of building layout information. In educational institutions we often find the medium of building layout information with a standard square form so that it is less inviting people's attention to see the media on an educational institution. State Polytechnic Samarinda as an educational institution has a building Directorate as a place to perform various activities related to activities that have a maket State Polytechnic Samarinda as a medium of information about the layout of the building of State Polytechnic Samarinda which can be read by the civitas academica State Polytechnic Samarinda. The maket in the Directorate still lacks. It can be seen from the standard square design form. The aesthetic form has a deficiency that there is a sharp angle on the part of the model often unintentionally injure the users. In addition, so far the existing model in the Directorate of State Polytechnic Samarinda has no other functions. From these backgrounds, it is necessary to design the infographic board that is designed as needed and has an additional function as a brochure so it is more effective to use because it is more functional, more durable and can attract the interest of the reader.
\end{abstract}

Keywords: Infographic board, Display, Stand

\section{Latar Belakang}

Politeknik Negeri Samarinda atau disingkat Polnes adalah sebuah Perguruan Tinggi Negeri yang terletak di Samarinda, Kalimantan Timur. Sebelumnya bernama Politeknik Universitas Mulawarman, yang resmi berdiri berdasarkan surat keputusan Direktorat Jendral Pendidikan Tinggi No. 080/Dikti/Kep/85 tertanggal 03 Desember 1985. Polnes memiliki lokasi kampus di Jalan dr. Cipto Mangunkusumo, Kecamatan Samarinda Seberang dengan luas lahan 10 hektar, yang dilengkapi dengan gedung Direktorat, Ruang Kuliah, Ruang Serba Guna, Gedung Laboratorium dan Bengkel, Gedung Perpustakaan, Gedung Pusat Komputer, Gedung Pusat Bahasa, Gedung Pusat Kegiatan Kemahasiswaan dan Gedung Penunjang lainnya.

Dari tahun ke tahun, Polnes memiliki banyak perubahan dari segi Jenjang Pendidikan maupun Infrastruktur pembangunan. Pada Tahun Ajaran 2008/2009, Politeknik Negeri Samarinda terus berkembang dengan bertambahnya 4 Jurusan baru, 3 diantaranya adalah Program Studi yang telah berkembang menjadi JurusanSehingga 56 total POLNES memiliki 10 Jurusan dengan 17 Program Studi.

Politeknik Negeri Samarinda yang berkembang dengan pesat, khususnya pada bagian Infrastruktur pembangunan, yang sampai sekarang masih terus berkembang membuat para pengunjung atau tamu Polnes akan sulit memahami tata letak gedung gedung yang ada di Polnes. Kesulitan para Tamu mengenai banyaknya gedung yang ada di Polnes dapat teratasi dengan cara memberikan sarana info grafik untuk pengunjung tentang Tata letak bangunan - bangunan yang ada di Polnes.

Infographic atau infografik menurut Doug Newsom dan Jim Hynes dalam bukunya Public Relations Writing (2004), Infografik adalah visual grafis yang menampilkan representasi dari informasi, data dan pengetahuan. Infografik menyajikan informasi yang cepat, jelas, dan kompleks, seperti tanda, peta, jurnalisme, pendidikan, dan pengetahuan. Dengan infografik, informasi akan lebih mudah diproses.

Dengan adanya penjelasan di atas, diperlukan suatu rancangan produk papan 
Vol. 6, No. 1, Oktober 2018

infograph untuk Politeknik Negeri Samarinda yang memudahkan pengunjung atau tamu untuk mengetahui denah lokasi gedung-gedung yang berada di Politeknik Negeri Samarinda, mudah dipahami dan memiliki bentuk yang estetis sehingga pengunjung tertarik untuk mengamatinya.

\section{Metode Perancangan}

Dalam merancang atau mendesain produk ini agar perancangan lebih terarah, digunakan metode perancangan Goel Vinod (1995) dengan langkah seperti berikut ini.

\subsection{Perumusan Masalah}

Media informasi tata letak bangunan yang ada di Politeknik Negeri Samarinda saat ini hanya berupa maket yang diletakkan di dalam gedung Direktorat memiliki desain yang standard dan tidak memiliki fungsi lain.

\subsection{Tinjauan Pustaka}

Studi eksisting terdiri dari definisi eksisting beserta jenis fasilitas eksisting papan infografik yang sudah ada. Teori segmentasi terdiri dari segementasi geografis, segmentasi demografis, segmentasi psikografis, segmentasi perilaku dan segmentasi manfaat. Teori ergonomic dan anthopometri untuk pengguna papan infografik. Teori system yang digunakan pada papan infografik, sistem sambungan, dan sistem finishing. Teori material besi dan material pendukung lainnya yang akan digunakan pada papan produk. Teori bentuk yang digunakan berdasarkan pendekatan bentuk gaya desain. Teori warna yang digunakan berdasarkan psikologi warna.

\subsection{Analisis \& Spesifikasi Desain}

Analisis pasar, studi aktifitas dan kebutuhan, analisis ergonomi \& anthopometri, analisis konfigurasi, analisis material, analisis bentuk, analisis warna dan analisis produksi. Spesifikasi desain (pengguna, dimensi, komponen, konfigurasi, sistem, material, bentuk, dan warna) untuk produk.

\subsection{Desain Alternatif}

Beberapa Desain alternatif papan infografik Polnes dan analisanya untuk didapatkan desain terpilih.

\subsection{Pengembangan Desain Alternatif Terpillih \\ Pengembangan desain alternatif terpilih menjadi beberapa alternatif, selanjutnya di- analisa untuk didapat desain final.}

\subsection{Desain Akhir}

Hasil desain akhir yang terdiri atas Gambar presentasi, Gambar teknik, Model produk, Prototipe.

\section{III.Pembahasan \\ 3.1. Studi Aktivitas dan Kebutuhan}

Analisis aktivitas dan kebutuhan dilakukan untuk mengetahui aktivitas - aktivitas yang dilakukan berkaitan dengan produk yang akan dibuat sehingga diperoleh daftar kebutuhan pengguna. Berdasarkan kebutuhan tersebut maka dibuatlah pemecahan dalam memenuhi kebutuhan tersebut dan mengaplikasikannya pada produk.

Berdasarkan analisis aktivitas dan kebutuhan yang telah dilakukan didapatkan kesimpulan mengenai komponen-komponen apa saja yang harus ada dalam produk. yaitu:

1. Memiliki bidang datar untuk meletakkan infografik

2. Memiliki penutup pelindung kaca infografik agar terhindar dari media informasi.

3. Memiliki logo Politeknik Negeri Samarinda sebagai identitas Universitas.

\subsection{Analisis Ergonomi dan Anthropo- metri}

Analisis ergonomi dilakukan untuk mengedepankan faktor kesehatan dan keselamatan dan juga kenyamanan dalam melakukan kegiatan menggunakan produk dapat maksimal. Ergonomi diperlukan untuk merancang suatu produk. Aktifitas-aktifitas yang telah dianalisis membutuhkan 
fasilitas yang ergonomis agar kenyamanan pengguna ketika menggunakan produk terjamin.

Ergonomi disini adalah kenyamanan dan keamanan yang diperlukan untuk melakukan aktivitas dengan produk papan infografik yaitu dengan menggunakan material yang tidak berbahaya untuk menghindari adanya sudut-sudut yang tajam pada setiap sisinya yang bersentuhan langsung dengan manusia.

Setelah studi aktivitas dan kebutuhan produk, maka dapat ditentukan anthopometri yang perlu digunakan untuk produk sehingga dapat suatu batasan dimensi produk. Anthopometri yang dibutuhkan, yaitu:

1. Tinggi papan infografik

Bidang visual optimum saat membaca pengumuman dengan jarak $100 \mathrm{~cm}$ dari papan infografik yakni sebesar $201 \mathrm{~cm}$, sehingga tinggi maksimal papan infografik yang digunakan adalah $200 \mathrm{~cm}$. Tinggi bidang visual optimum dari lantai yakni $90 \mathrm{~cm}$ yang merupakan ruang sebagai tempat peletakkan brosur dan majalah.

2. Lebar Papan Infografik

Lebar papan infografik menggunakan $50 \%$ persentil wanita Hongkong dengan range vision optimum $118 \mathrm{~cm}$ untuk lebar maksimal produk. Sehingga ukuran yang digunakan adalah $110 \mathrm{~cm}$. ukuran tersebut diasumsikan sebagai lebar papan infografik untuk lebar kertas infografik yang berukuran $80 \mathrm{~cm}$ dan selebihnya untuk space aksen ukiran dayak.

\subsection{Analisis Konfigurasi}

Analisis konfigurasi dilakukan untuk mendapatkan susunan atau konfigurasi dari tiap-tiap komponen yang terdapat pada papan infografik. Untuk mengetahui apa saja dan bagaimana perancangan papan infografik sesuai dengan data pengguna, maka perlu mengetahui gambaran atau denah produk tersebut.

Dari analisis konfigurasi yang telah dilaksanakan, dipilih alternatif konfigurasi dalam gambar 1. Pada analisis dalam gambar 1, posisi ukiran dayak berada di samping infografik diletakkan secara berdampingan. Posisi tersebut akan memberikan nilai estetis yang dapat menarik perhatian pengguna apabila hendak membaca infografik dan logo Politeknik Negeri Samarinda diletakkan tepat di atas kertas Infografik dengan ketinggian yang tepat sehingga membuat pembaca lebih leluasa dan nyaman dalam melakukan aktivitasnya.

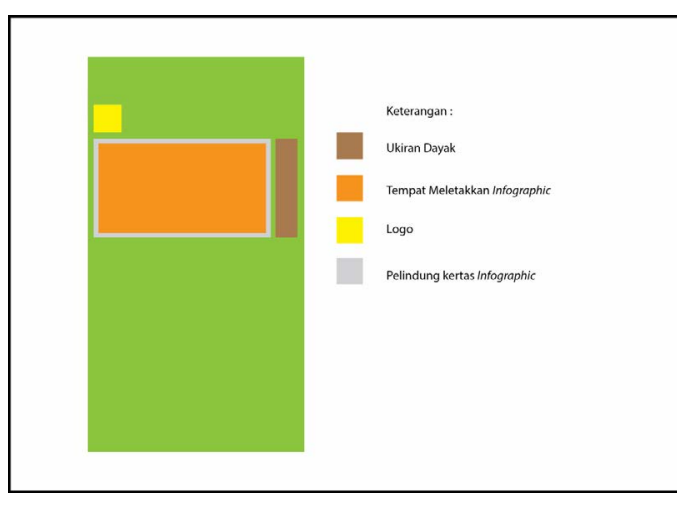

Gambar 1. Alternatif Konfigurasi terpilih

\subsection{Analisis Sistem}

Analisis sistem dilakukan guna menentukan sistem apa yang akan digunakan pada produk. Papan infografik ini menggunakan sistem perancangan yang sama dengan mebel pada umumnya. Berikut beberapa sistem yang digunakan:

\section{A. Sistem Sambungan Besi dengan Besi}

Dari beberapa analisis sistem sambungan besi dengan besi, maka sistem sambungan dengan las yang dipilih untuk diaplikasikan pada perancangan produk ini karena sistem sambungan menggunakan las lebih mudah digunakan pada proses pengerjaanya dan lebih cocok untuk menguhubungkan komponen-komponen yang sifatnya permanen.

Keuntungan menggunakan teknik las adalah menghasilkan sambungan yang permanen dan lebih kuat jika menggunakan teknik pengelasan yang tepat. Namun, 
Vol. 6, No. 1, Oktober 2018

kekurangan dari teknik las ini adalah hasil las sulit untuk dibongkar karena hasil dari pengelasan merupakan sambungan permanen sehingga jika konstruksi las ingin diganti maka konstruksi tersebut harus dirusak.

\section{B. Sistem Sambungan Akrilik dengan Komposit}

Dari beberapa analisis sistem sambungan akrilik dengan komposit, maka sistem perekat dengan baut display dipilih untuk diaplikasikan pada perancangan produk, karena sistem sambungan menggunakan baut display lebih mudah digunakan pada proses pengerjaanya dan lebih cocok untuk menguhubungkan komponen-komponen yang sifatnya permanen.

\section{Sistem Perekat}

Dari beberapa analisis sistem perekat dengan sekrup yang yang dipilih untuk diaplikasikan pada perancangan produk ini, karena sistem perekat menggunakan sekrup lebih mudah digunakan pada proses pengerjaannya.

\section{Sambungan Besi dengan Tanah}

Dari analisis sambungan besi dengan tanah yang telah dilaksanakan, ditentukan jenis sambungan semen. Semen akan diaplikasikan pada bagian alas papan infografik. Semen dipilih karena dapat menahan produk dengan baik.

\section{E. Finishing}

Dari analisis yang telah dilaksanakan jenis finishing yang dipilih untuk diaplikasikan pada produk ini yaitu Komposit. Komposit akan diaplikasikan pada bagian badan papan infografik. Komposit dipilih karena tahan korosi dan tepat untuk diletakkan di outdoor. Selain itu finishing dengan HPL memiliki tampilan yang lebih alami, mewah, dan memiliki pilihan warna yang cukup banyak serta lebih praktis digunakan.

\subsection{Analisis Material}

Analisis material dilakukan guna menentukan material baik yang akan digunakan pada produk ini, sehingga menghasilkan produk yang aman dengan kegiatan pengguna. Terdapat beberapa jenis material yang akan digunakan karena produk ini memiliki konsep ekletik dimana perlu menggabungkan beberapa jenis material yang berbeda menjadi satu kesatuan dengan tampilan yang estetis. Berikut beberapa material yang digunakan pada produk:

\section{a. Material Utama}

Material utama pada perancangan produk hasil dari analisis yang telah dilaksanakan adalah material besi. Tekstur lapisan besi rapat, sehingga memiliki kekuatan yang lebih baik dan daya tahan terhadap air lebih kuat.

\section{b. Material Pendukung}

beberapa material pendukung yang digunakan pada produk ini yaitu :

- Material Penempatan Logo Politeknik Negeri Samarinda menggunakan stainless. Stainless memiliki sifat tahan korosi, rendah perawatan dan kuat.

- Material pelindung kertas Infografik

Akrilik merupakan material yang memiliki warna bening transparan, tidak hanya sekedar bening, Akrilik juga sedikit menyerap sinar yang melalui media tersebut. Akrilik memiliki tampilan yang transparan seperti Kaca namun tidak mudah pecah. Akrilik bersifat elastis, sehingga secara teknis lebih dapat bertahan pada hentakan. Akrilik juga tidak berlumut..

\subsection{Analisis Bentuk}

Analisis bentuk diperlukan guna mencapai kenyamanan melalui bentuk yang sesuai fungsi dan juga anatomi tubuh manusia terhadap produk papan infografik Politeknik Negeri Samarinda ini.

Tema yang ada di sekitar area peletakkan papan infografik yaitu pada area Po- 
liteknik Negeri Samarinda, sebagian besar terdapat unsur etnik. Jika papan infografik Politeknik Negeri Samarinda menggunakan bentuk etnik seperti banyak ukiran bentuk enggang atau bentuk-bentuk etnik yang lain, yang mewaikili Dayak. Maka kesan formal sebagai Institusi Pendidikan akan kurang terlihat, meskipun akan terlihat punya kesatuan dengan tema yang ada disekitar. Jika dibandingkan dengan gaya postmodern yang diwakili oleh ekletik, maka kesan formal tetap terlihat misalnya dengan penggunaan gaya desain modern tetapi akan terlihat mempunyai kesatuan juga dengan tema yang ada di kawasan digabungkan dengan ekletik. Sehingga pada perancangan produk papan infografik ini terdapat unsur etnik dan postmodern ekletik yang akan diselipkan. Dimana konsep ekletik adalah penggabungan gaya dan material menjadi satu kesatuan untuk mencapai tampilan yang estetis.

\subsection{Analisis Warna}

Salah satu unsur desain yang perlu dianalisis secara cermat adalah pemilihan warna yang akan dipergunakan dalam desain produk. Warna memiliki karakteristik dan dampak estetis psikologis dalam desain papan infografik.

Analisis warna dilakukan untuk menemukan warna apa yang akan diaplikasikan pada produk. Dimana terdapat warna yang mendominasi serta warna yang digunakan sebagai aksen. Warna-warna dominan yang berpotensi digunakan adalah warna hijau, merah, kuning, dan hitam. Warna hijau mewakili warna indentitas Politeknik Negeri Samarinda, sedangkan warna merah, hitam, dan kuning mewakili warna etnik. Karena papan infografik diletakkan di Politeknik Negeri Samarinda maka warna yang mewakili paling mendominasi adalah warna hijau, sedangkan warna merah, hitam, dan kuning merupakan warna-warna kombinasi untuk warna hijau.

Selain warna tersebut perlu ada warna yang menjadi aksentuasi agar produk terlihat lebih estetis. Warna yang bisa dija- dikan aksentuasi yaitu warna coklat. Warna tersebut dipilih sebagai warna aksentuasi yang akan digunakan pada motif etnik Dayak. Warna coklat dipilih karena dirasa tepat untuk digunakan pada ukiran Dayak.

\subsection{Proses Desain}

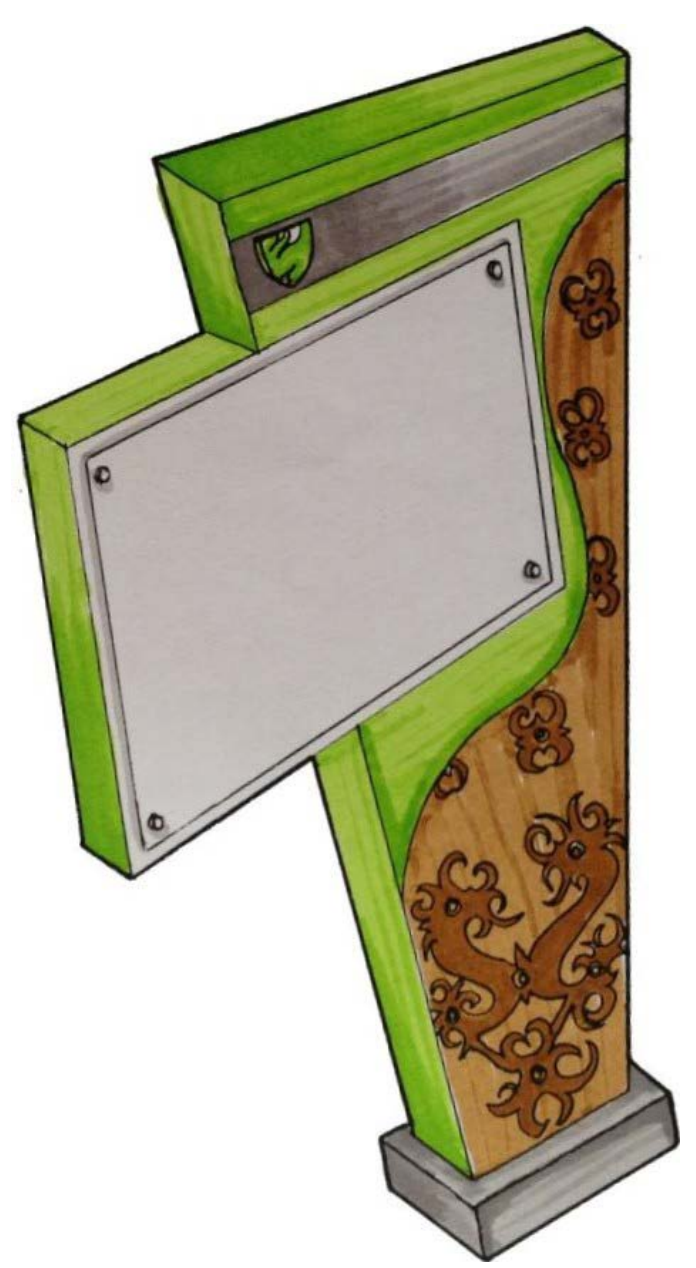

Gambar 2. Alternatif desain terpilih

Desain alternatif dalam gambar 2 ini penggunaan stainless tidak terlalu banyak sehingga dapat mengurangi biaya produksi dan memiliki bentuk yang tidak terlalu memakan banyak bahan produksi. Sedangkan untuk kekurangannya adalah penggunaan material akrilik cukup banyak pada desain ini. 
Vol. 6, No. 1, Oktober 2018

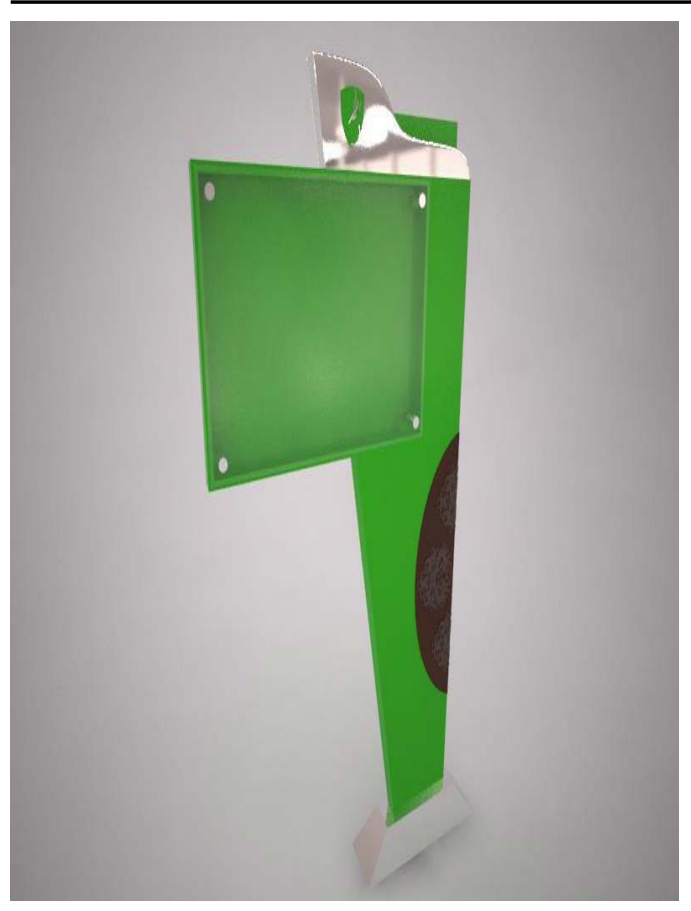

Gambar 3. Final Desain

\section{Kesimpulan}

Berdasarkan hasil perancangan dan pembuatan "Desain Papan Infografik Politeknik Negeri Samaarinda" maka dapat ditarik kesimpulan sebagai berikut:

Papan infografik ini menggunakan konsep gaya postmodern Ekletik, dengan menggunakan warna identitas Politeknik Negeri Samarinda yaitu Hijau sebagai dominan. Tujuan pada perancangan produk ini adalah merancang sebuah papan sebagai media informasi tata letak bangunan Politeknik Negeri Samarinda dan dapat digunakan dalam jangka panjang. Serta dengan menyesuaiakan tema desain interior yang ada di sekitarnya yaitu etnik Dayak Kenyah. Papan Infografik ini di desain menggunakan material yang tepat untuk kondisi outdoor karena memiliki kelebihan yaitu tahan korosi.

Saran yang dapat diberikan adalah bagi para produsen dan desainer agar perlu diadakan redesign untuk inovasi sistem papan infografik. Serta fungsi yang dapat disesuaikan dengan keinginan konsumen. 
Dwi Cahyadi, Apri Yani Nur Adilla, Desain Papan Infografik Untuk Politeknik Negeri Samarinda

\section{DAFTAR PUSTAKA}

Nurmianto Eko, (1998). Ergonomi Konsep Dasar dan Aplikasinya. Edisi Pertama Cetakan Kedua. Jakarta: Guna Widya

Panero Julius, AIA,ASID dan Zelnik Martin, AIA,ASID. (2003). Dimensi manusia dan ruang interior. Jakarta: Erlangga

Royan, Frans M, Marketing celebrities: Dalam Iklan dan Strategi Selebriti

IKJ Supriyadi. (2014). Buku Ragam Hias Ornamen Khas Kaltim. Samarinda: Dinas Perindagkop dan UKM Provinsi Kalimantan Timur. 